\title{
Adaptive Reasoning of Students in Solving Beam Problems in Elementary School
}

\author{
Isnafarinda Andriyani ${ }^{1}$, Tatag Yuli Eko Siswono ${ }^{2}$, Rooselyna Ekawati ${ }^{3}$ \\ Study Program of Primary Education, Postgraduate, State University of Surabaya \\ Surabaya, Indonesia
}

\begin{abstract}
This study aims to describe the adaptive reasoning of students in solving beam mathematical problems with high, medium, and low mathematical solving abilities. The research location is at Siti Aminah Surabaya elementary school, with 24 students in grades VI-A and will take 3 students as research subjects. This study uses qualitative research, by conducting several stages, namely, preparation, implementation, and analysis. Data analysis techniques used observation methods, tests of ability to solve mathematical problems (TPMM), and interviews. The results showed students with high mathematical abilities students were able to collect data then identify the components of the building blocks, be able to provide evidence and explanations and verify what he had obtained. Students with mathematical abilities while students are able to understand the problem by reading repeatedly to be able to explain and verify their findings. Students with low mathematical abilities are able to understand after doing trial and error, understanding from many data sources. From the experience and data sources obtained by students, they are only able to understand the problems, construct and connect with objects around them, gather information, so they can provide an explanation of the concept and verify it.
\end{abstract}

\section{INTRODUCTION}

Mathematics as one of the tools that can be used in developing the ability to think logically, systematically, analytically, critically, creatively and able to work together in solving problems. Learning mathematics related to the ability to understand concepts is very important in terms of its application in every other field of science and in everyday life. This is permitted as a Competency Standards for Mathematics Graduates for elementary and secondary education units (Minister of National Education Republic of Indonesia Regulation No. 24, 2006 ). Learning mathematics at every level of the school always focus on the basic objectives of mathematics itself, namely the formal goals related to the structuring of reason and material objectives related to the application of mathematics in the field of science (Soedjadi, 2000). This shows that the abstract nature of mathematical ideas allows students to apply mathematics to practice creating and realizing a systematic flow and to train the reasoning process that connects and adapts mathematical concepts that have been understood to the problem.
Starting from the results of observations of researchers in a number of sixth grade students at SD Siti Aminah Surabaya. They are given problems related to determining the value of the beam volume, they can solve it appropriately. Next students are given story problems related to the beam volume which allows students to display a varied approach in adapting their knowledge and experience. Namely "in a tourist vehicle there are 5 pools of the same size. The pool is $16 \mathrm{~m}$ long, $12 \mathrm{~m}$ wide and 1.5 $\mathrm{m}$ high. two pools filled with water to the full and the other three ponds filled only half. What is the volume of water needed to fill it ". Then students are given time to solve the questions.

The result is that there are several assessments that vary based on students' written solutions. Some students give up and cannot solve the problem because they cannot adjust the mathematical concepts to the problem situation. This shows that the students' adaptive reasoning is lacking when students are not familiar with the concept of the cube and the beam. with the problem situation. While some other students know the concepts that are appropriate to the problem situation but don't know what to do to direct the problem situation to the right solution means they cannot use strategies and methods to apply mathematics to the situation.

Solving problems is not only focused on understanding mathematical concepts, but also requires adaptive reasoning and strategy. Adaptive reasoning is needed because applying mathematics to problem situations requires mental activity in logically adjusting concepts, facts, methods, procedures to problem situations using previous experience to produce an idea in the form of solution solutions. Adaptive reasoning is one of several parts of reasoning that is precisely used to solve the condition of a problem. While reasoning is related to mental activities logically link between ideas (premises) so as to produce a conclusion and justify the conclusion based on knowledge that has been previously known.

The above description is in accordance with the emphasis on the standard content of the instruction process, which is developing the ability of reasoning through problem solving, communicating ideas and understanding through multi representations and linking mathematical ideas through their application (NCTM, 2000). Besides adaptive reasoning and strategic competence is a form of success and primacy in learning because it is not only seen from the ability to the solution, but also able to think logically to provide an explanation, justification and 
reflection on the results of thought and solution strategies used in the process of solving mathematical problems (Skemp , 1976; Kilpatrick, Swafford, \& Findell, 2001; Herbert, 2014).

The challenges of mathematical problems also contribute to stimulating students' adaptive reasoning. In accordance with the conclusion of the research results of Samuelsson (2010, p.71) that 'students' progress in conceptual understanding, strategic competence and adaptive reasoning is significantly better when teachers teach with a problem-based curriculum'. This means that students 'progress in conceptual understanding, strategic competence and adaptive reasoning is significantly better when teachers teach through the problem-based curriculum. Ostler (2011, p. 17) proposes a dynamic instructional task to stimulate and foster students' adaptive reasoning. Provision of mathematical problems proper instruction can develop students' adaptive reasoning (Groves, 2012).

Continuation of the initial observations that have been revealed by researchers at the beginning also shows the results that there are differences between one student with another. Another reason is that adaptive reasoning is based on the fact that students in Indonesia have low adaptive reasoning. This can be seen from the participation of Indonesia in participating in the PISA (Program for International Student Assessment) that since 2000 - 2012, Indonesia has always been ranked above 38 out of 65 countries (PISA, 2013). The PISA math test directs students to adapt mathematical concepts to problem situations in daily life and activates all the competencies they have to solve these problems as an extension of their mathematical knowledge content (PISA, 2013). Based on the description above, researchers are interested in conducting research on " Adaptive Reasoning Students in Solving Mathematical Problems of Cubes and Beams in Elementary Schools ".

This study aims (1) to describe the adaptive reasoning of students with high mathematical abilities in solving beam problems in elementary school; (2) describe the adaptive reasoning of students with mathematical abilities in solving beam problems in elementary school; (3) describe the adaptive reasoning of students with low mathematical abilities in solving beam problems in elementary school.

\section{THEORETICAL FRAMEWORK}

\section{$>$ Reasoning}

Reasoning is a logical thought process to produce conclusions using existing knowledge in cognitive structures. The resulting conclusion is logical or also called valid and true because it is based on facts, concepts, procedures, and methods so that it can be said that reasoning is a mental activity in thinking according to the rules of logic.
Reasoning is to use logic in drawing conclusions based on premises or in other words connecting several statements to produce ideas. Reasoning begins with the existence of some initial statements or premises can be in the form of facts or principles, then processed logically to produce a new idea. In accordance with the opinion of Copi (1990) that reasoning is a thought process to form a conclusion based on premises. Furthermore, in Ball, \& Bass Muller \& Maher, 2009 that reasoning is a process that allows the review and reconstruction of previous knowledge to build new arguments. The ability to reason can support the development of student knowledge.

Mathematical reasoning is central to learning mathematics (Russel, 1999). The form of mathematics learning outcomes is a change in student behavior towards mathematics. According to Francisco, \& Maher (2005) that students' behavior towards mathematics is influenced by the systematics of solving mathematical problems. Whereas learning and mathematical reasoning are an integral part of the process of solving mathematical problems. This opinion shows that mathematical reasoning connects several mathematical ideas to decide on a solution idea from a problem solving.

\section{> Adaptive Reasoning}

Kilpatrick, Swafford, \& Findell (2001, p.129) add that "In mathematics, adaptive reasoning is the glue that holds everything together, the lodestar that guides learning. One uses it to navigate through the many facts, procedures, concepts, and solution methods and to see that they all fit together in some way, that they make sense ...... .swers are right because they follow from some agreed-upon assumptions through series of logical steps, "

Broadly speaking Herbert (2014), Yook, \& Loong (2014) found in his research that adaptive reasoning includes the ability to make choices, tell, express clearly, compare, differentiate, explain, and justify themselves and others diagrams (writing) or verbal. This finding explains that adaptive reasoning is related to mental activities that can be seen through decisions and actions resulting in several choices. The choice is the result of thinking, so that through adaptive reasoning, students can provide clear words or through diagrams to tell, explain, compare, differentiate and justify the results of their thoughts to themselves and others.

Adaptive reasoning can be observed through the subaspects of the explanation and logical justification of ideas in the form of strategies (methods / procedures / facts) used as solutions, reflections on previous experiences that are relevant to the problem situation at hand and the logical justification of ideas (methods / procedures / facts ) which is used as a solution. 


\section{RESEARCH METHODS}

This type of research intends to find out students' adaptive reasoning in solving mathematical problems. Researchers study and uncover students' adaptive reasoning in solving mathematical problems beginning with asking the subject to solve mathematical problem solving, then proceed with interviews.

In this study, researchers will explore, describe or describe how students' adaptive reasoning in solving mathematical problems of geometry in geometric shapes in elementary school. According to Satori (2011) that research like this is classified as exploratory research using a qualitative approach.

This research was conducted at SD Siti Aminah by selecting 3 students as research subjects. The subjects of this study were students of class VI. The subjects in this study were 3 (three), each 1 (one) student with the ability to solve high (T), 1 (one) medium (SS), and 1 (one) low (SR) mathematical problems.

The material used in this study was the even 5 th grade elementary school material, namely beam volume material. The study was conducted in the 2019-2020 school year, the subjects in this study were students who had received the material in the 2018-2019 school year. The subjects were examined by being given a test of the ability to solve mathematical problems. After taking a test of the ability to solve mathematical problems, all three subjects were interviewed based on the results of the answers.

\section{RESULT AND DISCUSSION}

\section{$>$ Description of the determination of the research subject}

Mathematical ability in this study is based on scores obtained from students on the results of the Mathematics Ability Test. The following is a description of the students' ability to solve mathematical problems in the following table.

\begin{tabular}{|c|c|c|}
\hline $\begin{array}{c}\text { Ability to Solve Math } \\
\text { Problems }\end{array}$ & Quantity & Percentage \\
\hline $\begin{array}{c}\text { Rendah } \\
(\text { Skor < 50) }\end{array}$ & 6 & $25 \%$ \\
\hline $\begin{array}{c}\text { Sedang } \\
(\text { Skor 50 - 75 ) }\end{array}$ & 9 & $37,5 \%$ \\
\hline $\begin{array}{c}\text { Tinggi } \\
(\text { Skor > 75 ) }\end{array}$ & 9 & $37,5 \%$ \\
\hline Total & 24 & $100 \%$ \\
\hline
\end{tabular}

Table 1:- The ability of students to solve mathematical problems

Table 1 describes that of the 24 students who took the ability test to solve mathematical problems, there were 6 (25\%) students had low mathematical problem solving abilities, $9(37.5 \%)$ had the ability to solve moderate mathematical problems, and $9(37.5 \%)$ has a high ability to solve mathematical problems.
After giving a mathematical ability test to all prospective research subjects, based on the description above the research subjects obtained are students with the ability to solve math problems low, medium and high as follows.

\begin{tabular}{|l|c|c|c|}
\hline No & Subject Name Initial & Score & $\begin{array}{c}\text { Subject } \\
\text { Code }\end{array}$ \\
\hline 1. & SA & 100 & ST \\
\hline 2. & QTB & 66 & SS \\
\hline 3. & AAK & 43 & SR \\
\hline
\end{tabular}

Table 2:- Summary of Selected Research Subject Descriptions

\section{A. Adaptive Reasoning Students with High Mathematical Ability}

Adaptive reasoning of students with high mathematical ability (ST) in solving mathematical problems through three stages, namely explaining, proving justification, and reflecting. ST tries to understand the problem by receiving information, forming mental images and drawing to be able to identify problems and solve solutions in the form of an appropriate formula. ST understands the problem if it is successful in obtaining the form of the problem to the solution solution. Likewise in previous experiences, ST understands story problems by reading, imagining, drawing, receiving information carefully then inputting data that is known and asked and looking for the right solution.

The above is in line with the description of Kilpatrick et al., that mathematical problems will be easily formed as a solution to the solution if the problem situation is understood first. Then Kilpatrick, Swafford and Findell added that before making a model of a problem situation as a solution to the solution, the students build mental images (mental images) first. Furthermore, in line with Chrles, Lester \& O'Fafer's recommendations that drawing is one strategy that can lead to the right solution (Elia, Heuvel, Panhuizen, \& Kolovou, 2009)

Next, after understanding the problem, ST makes the formulation of known information by re-describing all information known verbally and in the form of images based on their respective characteristics and is relevant to mathematical concepts and facts. Furthermore, ST makes the formulation of the information requested by drawing and guessing-checking-revising through the process of image manipulation. ST captures concepts related to problem situations through other concept approaches first by functioning the important parts as a whole. ST tries to formulate the problem situation to find out a clear picture before moving on to the next solution. In line with the description of Kilpatrick, 2001 that the problem situation must be formulated in advance to be able to use mathematical facts as a solution to solve. In addition, ST processes all information received analytically on images related to all possible descriptions of the problem situation so that it captures the form of a solution to the solution. 
In the understanding stage, the subject identifies related concepts based on their nature and characteristics in the problem situation and based on the process of functioning of the core elements by paying attention to all the elements around them that influence the form of resolution based on their understanding and perception. Then, he justifies the conceptual relationship related to the problem situation is by revealing that the function of the core elements allows to produce a solution. Based on the explanation and justification of the concept related to the problem situation above, it can be concluded that ST identifies the image with the concept with the situation encountered in the function of the core elements. This is consistent with the definition of Tall \& Vinner, (1981) that describing concepts is the explanation of all images, traits and mental processes in cognitive structures connected to the concept. In addition, the explanation and justification above is related to ST thinking related to the relationship of mathematical concepts and problem situations. This is in line with the opinion of Kilpatrick, Swafford \& Findell 2001 that adaptive reasoning refers to logical thinking related to the relationship of mathematical concepts to problem situations.

At the stage of representing the problem situation, ST uses the image form by paying attention to the elements around it that affect the form of solution solutions, Identify the form of the settlement area that is produced by the function content of the element indirectly because it approaches another concept first and is based on the perception of its own understanding, produce their own form of representation related to the solution of the problem situation and in accordance with its cognitive structure.

Based on the explanation and justification of the form of representation verbally and through images, ST identifies the function of the core elements through another conceptual approach and considers all the elements around it that influence. Analyze the direction of the function of the core elements to produce a form of representation as a solution to the solution and adapt it to mathematical concepts, trying to build ideas by designing logical forms according to their perceptions and making calculations easier. ST decides the form of representation as the final solution through some initial allegations first. the explanation and justification above shows that ST connects the characteristics of the concept description related to the problem situation. this is in line with Groves's (2012) conclusion in his research results that adaptive reasoning arises in students if they try to provide an explanation and justification for the resulting solution method based on the situation at hand so that it is not just merely presenting the results of the form of representation that has been obtained. it is also in line with Ostler's (2011) definition that adaptive reasoning as the ability to think logically to provide reasons and justifications for the solution in accordance with the problem situation.
The picture made by ST in general is based on the concept of volume in the geometry of space, likewise when ST justifies the idea that when drawing two blocks of different sizes with the same water height, ST uses inductive reasoning based on analogy. this is consistent with the description of kilpatrick, Swafford \& Findell (2001) that adaptive reasoning also involves intuitive reasoning and inductive reasoning based on analogous and figurative patterns. In addition, Kilpatrick, Swaffird and Findell add that adaptive reasoning occurs when students justify solutions obtained through the relationship between concepts related to problem situations.

Furthermore, based on previous experience, ST tends to reflect on its learning experience when solving mathematical problems. Previous experience in solving mathematical problems greatly influences the strategies and procedures used when solving mathematical problems encountered and the patterns of explanation and justification used for thinking with concepts related to previous experiences. That is why ST recognizes and explains and justifies concepts related to problem situations using other conceptual approaches. This is in line with the opinion of Kilpatrick, Swafford \& Findell (2001) that students reflect on their experiences and use their knowledge gained from their experience of solution solutions.

\section{B. Adaptive Reasoning Students with Medium Mathematical Ability}

Adaptive reasoning ability of students with moderate mathematical ability (SS) in solving beam problems in elementary school through three stages, namely the stage of explaining, proving justification, and reflection.

In the explaining stage the SS understands the problem simply by imagining it as an attempt to receive all the information from the problem to know the core information and the form of the problem so that it can capture the core information and the purpose of the problem. Before explaining the problem the SS tried to make a mental picture. Thus the SS through the process of understanding the problem situation to prepare the next solution step to form a representation model. In line with the description of kilpatrick, Swafford, \& Findell (2001) that mathematical problems will be easily formed as a model of representation as the next solution step if the problem situation is understood first to be able to capture the core elements, then the SS formulates the known information and formulates the information stated by capturing the captured information structural relationships, give meaning and function in their entirety and comprehensively form appropriate and precise conceptual images through concrete objects. This is in line with the description of Kilpatrick, Swafford, \& Findell (2001) that solving problems must tend to focus on structural relationships in problem situations so that they are easily directed to solution solutions while also in line with the descriptions of Kilpatrick, Swafford, \& Findell that problem situations must be formulated first first to then be able to use mathematical facts as a solution to solving 
When understanding the SS explain and justify the relationship of concepts and their components associated with the problem situation by using a description of each concept believing that it has been through a process that is in accordance with the concept description related to the problem situation. According to Tall \& Vinner, (1981) that concept images are explanations of all the images of mental properties and processes in the cognitive structure connected to the concept. In addition, the description of the explanation and justification above is related to the thinking of a logical relationship between mathematical concepts and problem situations with those expressed by Kilpatrick, Swafford \& Findell (2001) that adaptive reasoning refers to logical thinking related to the relationship between concepts and problem situations.

Based on the explanation and justification of the form of representation, the SS identifies the form of the settlement area by considering all elements around the information that influence it to fulfill the information in question so that each part of the complex settlement area is divided into a number of settlement areas that are simpler in shape. The explanation and justification of the representation form indicates that the SS explains and justifies the representation form of the TPMM situation by linking the characteristics of the concepts related to the TPMM situation. This is in accordance with the conclusion of Groves (2012) in his research results, adaptive reasoning arises when students provide explanations and justifications for the solution methods that are generated from problem situations so that they do not merely present the solution to the solution. It is also in line with the definition of Ostler (2011) that adaptive reasoning as the ability to think logically to give reasons and justifications why the solution is suitable for the situation.

Justify the ideas generated by using the meaning of the observations in the picture then identify the concept based on the components that form the concept shows its adaptive reasoning by providing justification for its contents in the form of meaning absorbed from the form of images that contain the characteristics of the concept of images in accordance with the idea. According to kilpatrick, Swafford, \& Findell (2001) that adaptive reasoning occurs when students justify solutions obtained through the relationship of concepts related to problem situations.

Based on reflections on the previous experience SS remembers his experience constructing a concept into his cognitive structure so that he tends to find the idea of a solution to the solution during the reflection process therefore he can complete the procedure of the form of representation that is generated appropriately. In line with the expression Skemp (1982, p. 82) reflecting is realizing the relevant relationship between concepts that already exist in the cognitive structure with the existing problem situation. So that through reflecting activities, students have a mental image (mental image) associated with the relationship of concepts and mathematical problems.

\section{Adaptive Reasoning Students with Low Mathematical Ability}

Adaptive reasoning of students with low mathematical ability in solving beam problems in elementary school through three stages, namely the stage of explaining, proving justification, and reflection. SR tries to understand the problem from himself by accepting, imagining and drawing information per sentence information so that it makes it easier to identify the form and formula as a solution to the solution by directing the image into an easily understood form. SR observed the picture over and over again and tried to make sense of it through the drawing and made scratches of the calculation until it found the initial guess. SR also tried to understand it by imagining it in real life. In addition, the subject is trying from outside himself because he is not confident in his own perception. Thus it can be concluded that the SR understands the problem if it has obtained an initial picture of the direction of the solution solution. This is in line with the description of Kilpatrick, Swafford \& Findell (2001) that mathematical problems will be easily formed as a representation model as a solution to the solution if the problem situation is understood first.

After understanding the problem and obtaining a description of the direction of the solution to its solution, SR formulates the information that is known by identifying all information that is known in the form of illustrated images that are appropriate to the characteristics and concepts of mathematics. SR is confident and decides to illustrate the picture of the problem situation based on his inner perception and uses help from outside himself. Then express the conclusion as a determinant of the formation of a solution to solve it. Furthermore, SR formulates the information in question by re-describing information on the problem verbally and using pictures. SR gets a picture of the solution of the solution but through other forms of approach and uses concrete objects. direct the problem situation to find out an overview of the solution to the solution before moving on to the next solution. This is in line with the description of kilpatrick, Swafford \& Findell (2001) that the problem situation must be formulated in advance to be able to use mathematical facts as a solution to solve.

SR indirectly captures concepts related to problem situations and their components. based on its explanation and justification, SR identifies a concept description related to the problem situation at the function of an important part through concrete objects to find a solution. Trying to express a concept that has been built in the cognitive structure and adapted to the situation at hand. In line with what was expressed by kilpatrick, Swafford \& Findell (2001) that adaptive reasoning refers to logical thinking related to the relationship between concepts and situations. SR represents a problem using another concept approach first based on previous experience and based on the perception of his own understanding. 
SR identifies important information in a comprehensive way. This is caused by not being able to identify several problems that might be used as a solution to the solution. SR orientation finds a solution to its solution based on its ease of adjusting the shape of the region with a formula that is understood only. SR justifies the form of its representation by considering the appropriateness of its application in daily life and based on its understanding. This is in accordance with the conclusion of Groves (2012) in his research results that adaptive reasoning arises when students provide explanations and justifications for the solution methods that are generated from problem situations so that they do not merely present solution solutions. It is also in line with the definition of Ostler (2011) that adaptive reasoning as the ability to think logically to provide reasons and justifications for the solution in accordance with the situation.

Based on the justification of the SR idea using analogy. SR uses inductive reasoning based on analogy. This is in accordance with Kilpatrick, Swafford \& Findell (2001) that adaptive reasoning also involves inductive reasoning and inductive reasoning based on analogous and figurative patterns. In addition Kilpatrick, Swafford \& Findell added that adaptive reasoning occurs when students justify solutions obtained through the relationship of concepts related to problem situations.

Based on the reflection of previous experience, SR uses previous experience to decide the form of solution to the solution. Reflections on the concepts that are relevant and have been studied before and bring problem situations into the facts of everyday life This is in line with the opinion of Kilpatrick, Swaffird \& Findell (2001) that students reflect on their experiences and use the knowledge gained from these experiences to be used as solution solutions.

\section{CONCLUSION}

Based on the results of data analysis conducted to answer research questions, the research results can be concluded as follows.

Adaptive reasoning of students with high mathematical abilities in solving elementary school beam problems.

Students explain the strategies used in understanding mathematical problems by finding out information that is known, information that is asked, and the problem. He identifies each component of the related concept then explains and verifies verbally its relationship to the problem situation based on their respective characteristics. He corroborates with the picture when justifying the relationship. Based on previous experience, he tends to use related concepts in problems that have been solved before. Based on his explanation related to the procedure carried out, he uses the procedure appropriately and in accordance with each component that forms the concept used. He verifies the procedure verbally based on his belief in the suitability of the formula with the form obtained.
Adaptive reasoning students with high mathematical abilities in solving elementary school beam problems.

Students explain the strategies used in understanding mathematical problems by finding out information that is known, information that is asked, and the problem. He identifies each component of the related concept then explains and verifies verbally its relationship to the problem situation based on their respective characteristics. He corroborates with the picture when justifying the relationship. Based on previous experience, he tends to use related concepts in problems that have been solved before. Based on his explanation related to the procedure carried out, he uses the procedure appropriately and in accordance with each component that forms the concept used. He verifies the procedure verbally based on his belief in the suitability of the formula with the form obtained.

\section{> Adaptive reasoning students with mathematical abilities are in solving problems in elementary school blocks. \\ Students explain the strategies used in understanding mathematical problems by first reading to get all the data and information from the questions. Based on his experience, story problems can be drawn by reading repeatedly to find out the mathematical model. Likewise, when understanding a given problem, he forms a mental picture to find out the problem and capture core information and objectives. Then he imagined the problem in the problem before forming a mental picture to find out the form of the problem. He grasped directly the concepts that were appropriate to the problem situation and then explained and justified the relationship between the two logically based on the facts and their respective characteristics in their entirety and through their own language and images.}

Adaptive reasoning students with low mathematical ability to solve problems in elementary school blocks.

Students explain the strategies used in understanding mathematical problems by finding out and experimenting with formulas and searching in books or the internet and asking friends or asking to be explained. He understands the problem by forming mental images, drawing cases, observing, and asking questions. He explained that the strategy was in an effort to receive all information in the form of images, then he justified his strategy verbally oriented to the ease of finding out how to solve it and the formulas that were suitable. He uses his previous experience in understanding story problems because it makes it easy to imagine into real life and directs the situation to a more comprehensible picture. he then formulates information that is known by revealing Back with images that match the facts and characteristics and reveals the conclusions of the information received. Based on his explanation and justification, he identified the relationship of the related concepts and their components to the situation of TPMM in reality so as to produce a form of settlement that was in accordance with the concept. 


\section{REFERENCES}

[1]. Bieda, K.N., Ji., X., Drwencke, J., \& Picard, A. (2013). Reasoning-and-proving opportunities in elementary mathematics text books. International Journal of Educational Research. Journal homepage: www.elsevier.com/locate/ijedures. http://dx.doi.org/10.1016/j.ijer.2013.06.005.

[2]. Copi, I. M., \& Cohen, C. (1990). Introduction to logic. Eighth edition. New York: Maemillan Publishing Company.

[3]. Francisco, J. M., \& Maher, C. A. (2005). Conditions for promoting reasoning in problem solving: Insights from a longitudinal study. Journal of Mathematical Behaviour. 24:361-372.

[4]. Groves, S. (2012). Developing Mathematical Proficiency. Journal of Science and Mathematics Education in Southeast Asia, 35(2):119-145

[5]. Herbert, S. (2014) AFramework for teachers Knowledge of Mathematical Reasoning, In J. Anderson, M. Cavunagh \& A. Presscoll Eds, Curriculum in focus: Research guided practice. Proceedings of the $36^{\text {th }}$ annual conference of the mathematics Educations research group of Australasia. Hal 702-705. Sydey: MERGA

[6]. Killpatick, J., Swafford, J., \& Findell, B., (2001). Adding It Up. Washington: National Academy Press.

[7]. Ozdimer. I. E. Y., \& Pape, S.J. (2012). Supporting students strategic competence: A case of a sixth-grade mathematics classroom. Mathematics Education Resaerch Journal, 24(2), 153-168. DOI 10.1007/s13394-012-0033-8.

[8]. Ostler, E. (2011). Teaching Adaptive and Strategic Reasoning Through Formula Derivation: Beyond Formal Semiotic. International Journal of Mathematics Science Education, 4(2):16-26.

[9]. PISA. (2013). Result and Framework. didownload $\begin{array}{llll}\text { tanggal } & 10 & \text { Januari }\end{array}$ http://en.wikipedia.org/wiki/Programme for Internati onal_Student Assessment

[10]. Polya, G. (1973). How to solve it: A new Aspect of mathematical method. Princeton, NJ: Princeton. University Press.

[11]. Russel, S. J. (1999). Mathematical Reasoning in the Elementary Grades dalam Lee V. Stiff dan Frances $R$. Curcio. Developing Mathematical Reasoning in Grades K-12, 1-10. The National Council of Teachers of mathematics, Inc.

[12]. Satori, D., \& Komariah, A (2011). Metodologi Penelitian Kualitatif. Bandung: Alfabeta Bandung.

[13]. Samuellsson, J. (2010). The Impact of teaching Approaches on Students Mathematical Proficiency in Sweden. International Electronic Journal of Mathematics Education, 5 (2):61-78.

[14]. Soedjadi R. (2000). Kiat Pendidikan Matematika di Indonesia. Direktorat Jendral Pendidikan Tinggi: Depdiknas.

[15]. Suherman, E. (2003). Strategi Pembelajaran Matematika Kontemporer. Bandung:UPI.
[16]. Sukayasa, (200). Penalaran dan pemecahan masalah dalam pembelajaran Geometri. Prosiding Seminar Nasional Penelitian, pendidikan dan penerapan MIPA. Fakultas MIPA. Universitas Negeri Yogyakarta.

[17]. Zhu, Z., (2007). Gender Differences in Mathematical Problem Solving Pattern: A Review of Literature. International Education Journal, 8(2):187-203. 